\title{
KNOWLEDGE, ATTITUDE AND BEHAVIOR OF PEDIATRICIANS TOWARD ORAL HEALTH OF CHILDREN IN TANTA CITY
}

\author{
Mohamed Hassan El Bayoumi*
}

\begin{abstract}
Objectives: To assess knowledge, attitudes and behavior of pediatricians in Tanta city Egypt regarding children oral health, and to determine their will to integrate preventive dental education and procedures in their daily clinical practice.

Background: Increasing pediatrician's involvement in oral health promotion during child check up visits will improve children oral health especially those difficulty getting professional dental care. However, pediatricians' knowledge about preventive oral health, their readiness to participate in prevention and pediatricians' perceived barriers in professional dental referral are not clear.
\end{abstract}

Study design: An observational cross-sectional study was carried on 63 pediatricians working in the clinics of 14 primary health care centers in Tanta city, Gharbiya Governorate, Egypt.

Results: Response rate of pediatricians was $82.54 \%$. Mean of $23.07 \%$ of respondents were willing to apply fluoride varnish, $11.53 \%$ consider white spots as a marker of early dental decay. All participants (100\%) stated they had not been instructed in oral health neither in medical school, during residency nor through CME courses. Fifty percent of respondents reported having seen caries in school-aged children at least once per month. Percentage of pediatricians found difficulty to refer patients who are tow years old or less was $67.30 \%$, followed by difficulty in referring patients who had developmental delay $(61.53 \%)$.

Conclusion: Based on the result of the current study, it becomes clear that pediatricians suffer from lack of knowledge and time to take greater role in the oral health promotion of children furthermore they face many barriers for professional dental refer.

* Lecturer, Pediatric Dentistry, Oral Health and Preventive Dentistry Department, Faculty of Dentistry, Tanta University, Egypt 


\section{INTRODUCTION}

Children's oral health issues revolve around dental caries which is the most common chronic infectious disease of childhood and although can be reversed if dental intervention occurred early, its treatment is still the most prevalent unmet health need in children. ${ }^{1,2}$

Early Childhood Caries (ECC) is defined as the presence of one or more decayed, filled or missing a primary tooth in a child 72 months of age or younger ${ }^{3,4}$. It represents a serious public health problem in both developing and developed countries. ${ }^{5} \mathrm{ECC}$ has many consequences including aesthetic problems, pain, mastication difficulties and consequently reduction of quality of life of affected children. ${ }^{6}$

The American Academy of Pediatric Dentistry (AAPD) recommends that dental visits begin with first tooth eruption, typically during the first year of life for early caries risk assessment for the child, counseling and education of parents and beginning of preventive regimens like topical fluoride application..$^{7-9}$

Among all health professionals, pediatricians are in a unique position to effectively deliver preventive dental education and care because of the number of interactions pediatricians have with children during their first five years of age especially throughout the first year of life, which does not occurs in relation to dental queries ${ }^{10-12}$. Lewis et al., 2000 ${ }^{13}$ suggested that increasing pediatrician's involvement in oral health promotion during well-child care visits will ameliorate the oral health of children who has limited access for professional dental care. In 2003, pediatricians were involved in a United States strategic plan of oral health promotion ${ }^{14}$. Since that time, pediatrician's role in oral health has been fortified and recommendations for pediatric oral health risk assessments from 6 months of age are now included ${ }^{15-18}$.

So the aim of current research was to assess knowledge, attitudes and professional experience of pediatricians working in Tanta city primary care centers in regard to oral health of children, and to determine their willingness to involve preventive dental education and procedures into their daily clinical practices.

\section{SUBJECTS AND METHOD}

\section{Study design:}

An observational cross-sectional design was adopted for this work.

\section{Study setting:}

The present study was carried out in outpatient clinics of 14 primary health care centers in Tanta city, Gharbiya Governorate, Egypt.

\section{Target group:}

All pediatricians working in the clinics of 14 primary health care centers in Tanta city, Gharbiya Governorate were invited to participate in this study; pediatricians not willing to participate in the study were excluded.

\section{Collection of data}

The study was conducted to assess pediatricians' knowledge, attitudes and behavior regarding children's oral health. Though direct contact with the targeted pediatricians, they were invited to answer questionnaire developed and validated by Lewis et al., $2000{ }^{13}$ after taking her permission.

- The first section collected demographic data including practice type, number of years in practice, number of hours of previous oral health training, number of hours per week providing patient care and number of patients seen per week.

The survey questions were divided into 4 domains. These domains were:

1. Knowledge and familiarity with dental caries preventive therapies: this include true/false questions around knowledge of preventing dental caries; and yes/no questions concerning 
familiarity with dental sealants, fluoride varnish and whether pediatricians are qualified with these preventive technologies to illustrate it for patients.

2. Assessment of current practices and opinion on pediatricians' role in promoting oral health: participants evaluated their current performance of 6 oral health practices during a child check up visit on a 5- point scale ranging from very likely to very unlikely. Pediatricians also rated their agreement with practicing oral health activities as a part of their clinical daily practices on a 5 -point scale ranging from strongly agree to strongly disagree.

3. Fluoride varnish application: participants were asked whether they agree to apply fluoride varnish to patients. If the answer is "yes" they were asked about reimbursement rate for the procedure.

4. Experience with dental problems and barriers to professional dental care: participating pediatricians were rated the frequency they saw ECC (baby bottle tooth decay) and caries in schoolaged children on a 6-point scale ranging from at least once a week to never. Pediatricians also rated perceived difficulty in referring various categories of patients to professional dental care on a 5- point scale ranging from very difficult to not at all difficult.

\section{Statistical Analysis}

Data was collected, presented and descriptive statistics carried out using SPSS Statistical Package System v 22.

\section{RESULTS}

The present study were carried out among 52 pediatricians with a response rate of $82.54 \%$. Characteristics of the respondent pediatricians are presented in table (1). Results revealed that respondents have been in practice for 7.2 years. Information gathered showed that respondents works 40.7 hours per week in average during which they deliver medical care for a mean of 162.03 patients. All participants (100\%) reported that they had not been instructed in oral health neither in pregraduation nor post-graduation.

TABLE (1) Respondents' characteristics.

\begin{tabular}{|l|c|}
\hline Provider characteristics & Respondents \\
\hline Years in practice & 7.2 years \\
\hline Hour of instruction in oral health: mean (SD) & \\
Medical school & 0 \\
Residency & 0 \\
CME & 0 \\
\hline Respondents with no instruction in oral health: & \\
Medical school & $100 \%$ \\
Residency & $100 \%$ \\
CME & $100 \%$ \\
\hline Hours per week providing patient care: & 40.7 \\
Mean (SD) & $(17.64)$ \\
\hline Number of patients seen per week: & 162.03 \\
Mean (SD) & $(59.17)$ \\
\hline
\end{tabular}

Participants' replies to knowledge questions are represented in Table (2). Participants who correctly answered question about cavity-causing bacteria transmission were $67.30 \%$ and those who give correct answer for bottle-fed children were $40.38 \%$. When asking about white spots as a marker of early dental decay, the percentage of correct responses was $11.53 \%)$. However, answering questions regarding fluoride supplements and dental sealants, correct answers were only $7.67 \%$ and $5.77 \%$ respectively.

Table (3) displayed pediatricians' familiarity with the preventive dental procedures. Only $15.38 \%$ of pediatricians were familiar with fluoride varnish. Despite this, $23.07 \%$ were willing to apply fluoride varnish with average suggested reimbursement rate was $\$ 18.20$. In comparison, $13.46 \%$ of participants exhibited familiarity with dental sealants, however only $7.69 \%$ were ready to explain it to a patient. Seventy seven percent responded that they have no time to apply fluoride varnish. 
TABLE (2) Replay of participants on knowledge questions

\begin{tabular}{|l|c|c|}
\hline \multicolumn{1}{|c|}{ Question } & $\begin{array}{c}\text { Correct } \\
\text { response }\end{array}$ & $\begin{array}{c}\text { Percent } \\
\text { responding } \\
\text { correctly } \\
\mathrm{n}=52\end{array}$ \\
\hline $\begin{array}{l}\text { Only bottle-fed children get early } \\
\text { childhood caries }\end{array}$ & False & $\begin{array}{c}21 \\
(40.38 \%)\end{array}$ \\
\hline $\begin{array}{l}\text { Dental sealants are usually applied to } \\
\text { a child's primary teeth. }\end{array}$ & False & $\begin{array}{c}3 \\
(5.77 \%)\end{array}$ \\
\hline $\begin{array}{l}\text { Cavity-causing bacteria can be trans- } \\
\text { mitted between mother and child. }\end{array}$ & True & $\begin{array}{c}35 \\
(67.30 \%)\end{array}$ \\
\hline $\begin{array}{l}\text { A 3 month old baby living in a } \\
\text { nonfluoridated area needs fluoride } \\
\text { supplementation }\end{array}$ & False & $\begin{array}{c}4 \\
(7.67 \%)\end{array}$ \\
\hline $\begin{array}{l}\text { White spots in the teeth may indicate } \\
\text { early dental decay }\end{array}$ & True & $\begin{array}{c}6 \\
(11.53 \%)\end{array}$ \\
\hline
\end{tabular}

TABLE (3) Pediatrician familiarity with preventive dental care technologies

\begin{tabular}{|c|l|l|}
\hline \multirow{2}{*}{ Technology } & \multicolumn{1}{|c|}{$\begin{array}{c}\text { Percent } \\
\text { responding as } \\
\text { being familiar } \\
(\mathrm{n}=52)\end{array}$} \\
\hline Fluoride Varnish & Familiar & $8(15.38 \%)$ \\
\cline { 2 - 3 } & Reimbursement (\$) & $12(23.07 \%)$ \\
\hline Dental Sealants & Familiar & $7(13.20 \%)$ \\
\cline { 2 - 3 } & Familiar to explain & $4(7.69 \%)$ \\
\hline
\end{tabular}

Regarding Current practices and opinion toward promoting oral health, as shown in Table (4), only $23.07 \%$ of respondents agreed or strongly agreed that fluoride application should be a part of their routine work, yet a slightly higher percentage (34.61\%) agreed that an assessment for dental problems should be included during medical examination of children. Furthermore, $48.07 \%$ of pediatricians agreed to advise children and their caregivers on prevention of dental problems, and near one third $(32.69 \%)$ agreed that it is important to refer children to a dentist by twelve months of age.
Regarding incorporation of oral health practices into their appointments, percentages of pediatricians likely or very likely to incorporate oral health practices was as following: inquire whether a child is taking a bottle to bed (36.78\%), counsel on the importance of regular tooth brushing (32.69\%) and advise on the significance of visiting dentist $(23.07 \%)$. Pediatricians were less likely to examine the child's teeth for cavities $(9.61 \%)$, inquire about the mother's dental health $(7.69 \%)$ and assess children's fluoride intake (3.84\%).

TABLE (4) Assessment of current practices and opinion on the role of pediatrician in promoting oral health

\begin{tabular}{|l|c|}
\hline $\begin{array}{l}\text { Should the Following be a Part of } \\
\text { Routine Well-Child Care? }\end{array}$ & $\begin{array}{c}\text { Percept agreeing or } \\
\text { strongly agreeing } \\
\text { n=52 }\end{array}$ \\
\hline Referral to the dentist at 12 month of age & $17(32.69 \%)$ \\
\hline Application of fluoride varnish & $12(23.07 \%)$ \\
\hline $\begin{array}{l}\text { Assessment for dental problems during } \\
\text { the physical examination }\end{array}$ & $18(34.61 \%)$ \\
\hline $\begin{array}{l}\text { Counseling on the prevention of dental } \\
\text { problems }\end{array}$ & $25(48.07 \%)$ \\
\hline $\begin{array}{l}\text { How likely are you to do the following } \\
\text { in a Well-Child Care Visit? }\end{array}$ & $\begin{array}{c}\text { Percent likely or } \\
\text { very likely }\end{array}$ \\
\hline Assess fluoride intake & $2(3.84 \%)$ \\
\hline $\begin{array}{l}\text { Counsel on the importance of } \\
\text { toothbrushing }\end{array}$ & $17(32.69 \%)$ \\
\hline $\begin{array}{l}\text { Inquire whether a child is taking a } \\
\text { bottle to bed }\end{array}$ & $19(36.53 \%)$ \\
\hline Counsel on going to the dentist & $12(23.07 \%)$ \\
\hline Examine a child's teeth for cavities & $5(9.61 \%)$ \\
\hline Inquire about mother's dental health & $4(7.69 \%)$ \\
\hline
\end{tabular}

Data about the frequency of childhood caries seen in the pediatric office was displayed in Table (5). About quarter of respondents reported having seen caries in infants (26.92\%) and half of respondents $(50 \%)$ reported having seen caries in school-aged children at least once per month, while $15.38 \%$ and 
$28.35 \%$ saw caries at least once per week in these children, respectively.

TABLE (5) Prevalence of dental caries seen in children

\begin{tabular}{|c|c|}
\hline $\begin{array}{l}\text { How often do you see the following } \\
\text { in your practice? }\end{array}$ & $\begin{array}{c}\text { Percent reporting } \\
\mathrm{n}=52\end{array}$ \\
\hline $\begin{array}{c}\text { Early Childhood Caries } \\
\text { At least once per week }\end{array}$ & $8(15.38 \%)$ \\
At least once per month & $14(26.92 \%)$ \\
\hline Caries in school-aged children & \\
At least once per week & $15(28.84 \%)$ \\
At least once per month & $26(50 \%)$ \\
\hline
\end{tabular}

Difficulty in referring to professional dental care are presented in Table (6). Pediatricians found it to be much more difficult to refer patients who are tow years old or less $(67.30 \%)$, followed by difficulty in referring patients who had developmental delay $(61.53 \%)$, patients who were uninsured and had an emergent dental problem on the evenings or weekends $(23.07 \%)$ or uninsured and needed a sliding payment scale $(17.30 \%)$. In comparison, only $9.61 \%$ of pediatricians found it difficult to refer individuals who had private insurance to a dentist.

TABLE (6) Barriers of referring to professional dental care

\begin{tabular}{|l|c|}
\hline How difficult is it to refer a patient who & $\begin{array}{l}\text { Percent reporting } \\
\text { difficult or very } \\
\text { difficult } \mathrm{n}=52\end{array}$ \\
\hline Are $\leq 2$ years old & $35(67.30 \%)$ \\
\hline Have significant developmental delay & $32(61.53 \%)$ \\
\hline $\begin{array}{l}\text { Are uninsured and need a sliding } \\
\text { payment scale }\end{array}$ & $9(17.30 \%)$ \\
\hline $\begin{array}{l}\text { Are uninsured and have an emergent } \\
\text { dental problem on night/weekend }\end{array}$ & $12(23.07)$ \\
\hline $\begin{array}{l}\text { Have private insurance and have an } \\
\text { emergent dental problem on night/ } \\
\text { weekend. }\end{array}$ & $5(9.61 \%)$ \\
\hline
\end{tabular}

\section{DISCUSSION}

Despite global calls to strengthen oral health in pediatric practice, there were no studies have been conducted to assessed the knowledge and practice of Tanta city pediatricians in regard to children's oral health, therefore the present study was carried out to fulfill this point.

Different tailored instruments have been used to assess the role of pediatricians in oral health of children, however the questionnaire developed and validated by Lewis et al., $2000{ }^{13}$ was used because it includes sufficient questions to assess a knowledge, attitudes, professional experiences and offers comprehensive vision to pediatrician's involvement in preventive dental procedures ${ }^{19}$.

In the present study, analysis of demographic characteristics of the study sample revealed that participants had been in practice for a mean of 7.2 years compared to 13.7 years American national average reported by Lewis et al., 2000 ${ }^{13}$ and 16.9 years in study carried out by Roberts, $\mathbf{2 0 1 3}^{19}$. This finding mean that the main bulk of pediatricians working in Tanta primary health care centers are younger in age and easier to adopt new work strategies.

The current study respondents work 40.7 hours per week in average which is comparable to the result of studies carried out by Lewis et al., 2000 ${ }^{13}$ and Roberts, 2013 ${ }^{19}$ who reported that American pediatricians provide patient care for 39.6 and 37.0 hours every week respectively. However, the present work highlighted that respondents deliver medical care for an average of 162.03 patients during their weekly working hours which is higher than postulated by Lewis et al., 2000 ${ }^{13}$ and Roberts, $\mathbf{2 0 1 3}^{19}$ who reported 114.2 and 99.8 mean patients seen by pediatrician per week. This finding tells the deficiency of time for oral health care providing.

Though two thirds of Tanta primary health providers participating in the study could correctly answer knowledge question on cavity-causing bacteria transmission that is higher than American 
national average $39.5 \%$ reported by Lewis et al., $\mathbf{2 0 0 0}^{13}$, however it is less than the result of Tennessee providers $(77.1 \%)$ in study conducted by Roberts, $\mathbf{2 0 1 3}^{19}$, however, respondents in the present study fell short when asked questions regarding dental sealants and fluoride varnish (both preventive technologies), percent of correct answer was 7.67 $\%$ and $5.77 \%$ respectively in comparison to $60.8 \%$ and $37.3 \%$, highlighted by Lewis et al., 2000 ${ }^{13}$ and $52.5 \%$ and $29.5 \%$ in study carried out by Roberts, $\mathbf{2 0 1 3}^{19}$.

Regarding answer of knowledge question on bottle-fed, it was found to be nearly half of American national average reported by Lewis et al., 2000 ${ }^{13}$ and less than half of Tennessee providers postulated by Roberts, $\mathbf{2 0 1 3}^{19}$. These results confirm that pediatricians in primary health care centers of Tanta city did not receive education on oral health during medical school and residency programs as all respondents reported. This finding can also explain why relatively few (13-15\%) are familiar with preventive dental procedures, such as the application of fluoride varnish and only (23\%) believe that preventive dental technologies should be incorporated into their practices.

In regard to routine well-child care, although near half of pediatricians confirmed that they play a role not to be reckoned with in promoting oral health through counseling on the prevention of dental problems, the results revealed their overestimation of involvement. Less than one quarter agreed that fluoride varnish application should be a part of wellchild care provided by pediatricians. These findings are comparable to results of Lewis et al., $2000{ }^{13}$ and Roberts, $\mathbf{2 0 1 3}^{19}$. In this regard, the most frequent response fell into the disagree category suggesting the possibility that familiarity with fluoride varnish and fixed salary are not only the causes but also the number of children examined every hour.

Additionally, more than two thirds of pediatricians did not agree with the referral of children to the dentist by 1 year of age. The possible explanations of this finding are pediatricians may not be knowledgeable of the AAPD recommendation. In addition, pediatricians may be unaware that prevention of dental caries begins at this age. Moreover, some comments written on the survey inquire about dentists' willingness and ability to care for very young children.

The current work displayed that few pediatricians were inquiring about the mother's oral health (7.69\%) or assess the fluoride intake of the child $(3.84 \%)$. This result was in contrary to that of Lewis et al., 2000 ${ }^{13}$ and Roberts, $\mathbf{2 0 1 3}^{19}$ who found out that most of the pediatricians are likely to participate in anticipatory guidance and assessment practices. This different finding may be attributed to more time limitations on behalf of Tanta pediatricians as the mean number of patients seen every week was 162 during 40.7 mean hours of work, in addition to the deficiency of oral health knowledge.

The results of the current research confirmed that pediatricians frequently observe dental caries in school age children, that is on line with the results of Lewis et al., $\mathbf{2 0 0 0}^{13}$ and Roberts, $\mathbf{2 0 1 3}^{19}$, it was not surprising because dental caries remains the most common chronic disease affecting children ${ }^{20-22}$. On the other hand, participating pediatricians in the current study were less frequently observe early childhood caries compared to decay in school age children, this may be attributed to the fact that almost all participating pediatricians did not know that white spot in the teeth indicates early dental decay as shown in table (2).

This study identified some barriers that may limit pediatricians' effectiveness in regard to oral health promotion. First, pediatricians' knowledge of and familiarity with dental caries preventive technologies including dental sealants and fluoride applications were limited. If pediatricians are to play a valuable role in oral health promotion, they need adequate knowledge of recent dental preventive strategies. 
A second barrier is the perceived difficulty to refer many special groups of patients. More than two thirds of the participants reported difficult referral of children less than 2 years old, this is more than result of Lewis et al., 2000 ${ }^{13}$ and Roberts, $\mathbf{2 0 1 3}^{19}$ who reported $30 \%$ and $25 \%$ of respondents had difficulty referring 2 years old children.

In addition, more than half of participating pediatricians reported difficulty referring patients having significant developmental delay, this finding is more higher than that of Lewis $\mathbf{2 0 0 0}^{13}$ and Roberts $\mathbf{2 0 1 3}^{19}$ who reported $33.3 \%$ and $27.9 \%$ respectively.

On the other hand, only less than one tenth of participating pediatricians reported difficulty in referring uninsured patients, our finding is obviously less than that of Lewis et al, 2000 ${ }^{13}$ and Roberts, $\mathbf{2 0 1 3}^{19}$ who reported more than half of respondents had that difficulty, this is attributed to the fact that Egyptian dental health care system is either pay for service in private clinics or free treatment in university and ministry of health hospitals.

In the present study, the response rate of $82 \%$ is high in comparison to $62 \%$ in survey carried out by Lewis et al, 2000 ${ }^{13}$ and $13.8 \%$ in study of Roberts, $\mathbf{2 0 1 3}^{19}$, this may be attributed to the direct contact of the researcher with the target group of pediatricians.

\section{CONCLUSION}

It becomes clear that pediatricians suffer from lack of knowledge and time to take greater role in the oral health promotion of children furthermore they face many barriers for professional dental refer.

For valuable pediatricians incorporation in oral health promotion, the following is recommended:

1. Pediatricians should fulfill sufficient training in oral health care during medical school and post graduate education.

2. Recent information and guidelines of preventive dentistry should be the core of oral health knowledge for pediatricians.
3. Pediatricians must be ensured that all patients groups can receive professional dental care.

4. Pediatricians will require sufficient resources, however time pressure in addition to staff shortage will make it difficult for pediatricians to participate well in oral health care for all children.

\section{ACKNOWLEDGEMENTS}

I would like to express my special thanks to Dr. Charlotte W. Lewis, for allowing me to use her survey instrument.

In addition, I would like to express my sincere thanks to managers and pediatricians of primary health care centers of Tanta city for their help and participation in the study.

\section{REFERENCES}

1. Douglass JM, Douglass AB and Silk HJ. A practical guide to infant oral health. American family physician. 2004;70(11).

2. Newacheck PW, Hughes DC, Hung YY, Wong S and Stoddard JJ. The unmet health needs of America's children. Pediatrics. 2000;105:989-997.

3. Kaste LM, Drury TF, Horowitz AM and Beltran E. An evaluation of NHANES III estimates of early childhood caries. J Public Health Dent. 1999; 59: 198-200.

4. Drury TF, Horowitz AM and Ismail AI. Diagnosing and reporting early childhood caries for research purposes. J Public Health Dent. 1999; 59: 192-197.

5. Livny A, Assali R and Sgan-Cohen HD. Early Childhood Caries among a Bedouin community residing in the eastern outskirts of Jerusalem. BMC Public Health. 2007;7(1):167.

6. Inglehart MR. Oral health and quality of life. Behavioral dentistry. 2006:265-275.

7. $\mathrm{Ng} \mathrm{CK}, \mathrm{Ng} \mathrm{GC}$ and Paed D. Frequency of Pediatric Dental Visits of Age Groups in Cross-Sectional Samples Obtained Between 1997 and 2006. Oral Health. 2007;97(1):19.

8. Isong $U$ and Weintraub JA. Determinants of Dental Service Utilization Among 2 to 11 -Year -Old California Children. Journal of public health dentistry. 2005;65(3):138-145. 
9. Hale KJ. Oral health risk assessment timing and establishment of the dental home. Pediatrics. 2003;111 (5 Pt 1):1113-1116.

10. Barroso SP, Miasato JM, Graça TCA. Avaliação da freqüência de visitas ao Pediatra $\mathrm{x}$ visitas ao Odontopediatra em Unidade Básica de Saúde do Município de NiteróiRJ. J Bras Odontoped Odonto Bebe. 2001; 3(14): 324-327.

11. Mouradian W, Schaad D, Kim S, Leggott P, Domoto P, Maier R, et al. Addressing disparities in children's oral health: a dental-medical partnership to train family practice residents. J Dent Educ. 2003;67(8):886- 895.

12. Jones K. and Tomar S. Estimated impact of competing policy recommendations for age of first dental visit. Pediatrics, 2005.115(4):906-914.

13. Lewis C, Grossman D, Domoto P, and Deyo R. The Role of the Pediatrician in the Oral Health of Children: A National Survey. Pediatrics; 2000.106(6):84

14. US Dept of Health and Human Services, Public Health Service, National Institute of Health, National Institute of Dental and Craniofacial Research. National call to action to promote oral health. Rockville: National Institute of Dental and Craniofacial Research; 2003.

15. Lewis C, Cantrell D and Domoto P. Oral health in the pediatric practice setting: a survey of Washington state pediatricians. Pediatrics. 2004;64:111-114.

16. Lewis C, Boulter S, Keels M, Krol DM, Mouradian W, O'Connor K, et al. Oral health and pediatricians: results of a National Survey. Acad Pediatr. 2009;9(6):457-461.
17. Kressin NR, Nunn ME, Singh H, Orner MB, Pbert L, Hayes $\mathrm{C}$, et al. Pediatric clinicians can help reduce rates of early childhood caries: effects of a practice based intervention. Medical care. 2009;47(11):1121.

18. Lewis CW, Barone L, Quinonez RB, Boulter S and Mouradian WE. Chapter oral health advocates: a nationwide model for pediatrician peer education and advocacy about oral health. International Journal of Dentistry Volume 2013, Article ID 498906, http://dx.doi. org/10.1155/2013/498906

19. Roberts R, "The Role of the Pediatrician in the Oral Health of a Child: A Survey of Tennessee Providers" (2013).Baker Scholar Projects. http://trace.tennessee.edu/utk_bakerschol/11

20. United Nations General Assembly. Political Declaration of the High-level Meeting of the General Assembly on the Prevention and Control of Noncommunicable Diseases. Resolution A/66/L1. 2011

21. Kassebaum NJ, Bernabé E, Dahiya M, Bhandari B, Murray CJL and Marcenes W. Global burden of untreated caries: a systematic review and Metaregression. J Dent Res. 2015;94(5):650-8.

22. Global, regional, and national incidence, prevalence, and years lived with disability for 354 diseases and injuries for 195 countries and territories, 1990-2017: a systematic analysis for the Global Burden of Disease Study 2017. Lancet 2018; 392: 1789-8583. 